\title{
Can Peer Assessment Impact Self-efficacy During Small-Group Learning?
}

Lauren J. Germain, PhD, MEd | Hsin H. Li, DO, MPH | Amen Wiqas, BA | Lauren Zahn, MA |

Telisa M. Stewart, DrPH | Travis R. Hobart, MD, MPH | Amy E. Caruso Brown, MD, MSc, MSCS

PRiMER. 2022;6:1.

Published: 1/7/2022 | DOI: 10.22454/PRiMER.2022.353730

\section{Abstract}

Introduction: While studies report positive correlations between students' perceptions of the learning environment and their reported self-efficacy, the role of peer assessment is poorly understood in this context. This study examines the process and impact of peer assessment on self-efficacy and perceptions of the learning environment during a small-group discussion-based course required of first-year medical students.

Methods: After spending time in small-group learning, students completed three peer assessments and reviewed three assessments of themselves. Analysis of the peer assessments included thematic coding of comments and word counts. Prior to and following the assessment period, students completed a survey including the Generalized Self-efficacy (GSE) Scale, and six locally-developed questions regarding the learning environment and perceptions of peer assessment. We performed paired-sample $t$ tests to determine whether there were differences between the pre- and post-peer assessment surveys. The SUNY Upstate Institutional Review Board reviewed the study and determined it to be exempt.

Results: Peer assessment narratives referred most commonly to students' participation style and the need for greater participation. Word counts ranged widely. A paired sample $t$ test indicated that the difference between pre and post peer assessment GSE scores was significant $(P=.009)$, but the effect size was small $(d=0.32)$. Perceptions of the learning environment did not change after the peer assessments.

Conclusion: Peer assessment offers a potential strategy for enhancing self-efficacy in medical school small-group learning environments and requires few resources to implement, relative to the potential benefits.

\section{Introduction}

Postresidency professional growth is dependent on learning from one's colleagues, yet uncertainty about the quality and impact of peer assessment in higher education has hindered its adoption. ${ }^{1-3}$ Medical students may fear consequences of evaluative transparency in peer assessment both for themselves and their community. ${ }^{4}$ The learning environment is particularly important; positive learning environments promote the development of self-regulated learning behaviors, skills essential to personal and professional growth. ${ }^{5}$ While most studies report positive correlations between students' perceptions of the learning environment and their reported self- 
efficacy, ${ }^{6}$ the role of peer assessment is poorly understood in this context. This study examines the impact of peer assessment on self-efficacy and perceptions of the learning environment during a small-group, discussion-based course for all first-year medical students (MSIs).

\section{Methods}

At SUNY Upstate Medical University, MSIs take a required course in bioethics, public health, and related social sciences. The majority of course content is taught through case-based, small-group discussions. Groups of 10-12 students and two faculty facilitators meet throughout the year to discuss 22 cases.

\section{Pilot and Validity}

In 2017-2018, the purpose of peer assessment was shared with MS1s during a required training about the small-group experience, assessment system, and how to provide useful feedback to peers. During the course, all students were required to complete peer assessments using a form similar to the one used by faculty. Students were informed that the content of peer assessments would not impact grading, but would be reviewed for noncompletion and that the inclusion of unprofessional remarks would lead to an incomplete in the course and/or a professionalism concern report. Analysis of the assessment data and student responses established that the process and tool had face validity. The peer assessment tool is available on the STFM Resource Library.

\section{Study}

In 2018-2019, with the same training and policies in place, students completed three peer assessments after 9 hours of small-group discussion. In the weeks prior to and following the assessments, students were invited to complete surveys including the previously validated Generalized Self-Efficacy Scale ${ }^{7}$ (10 items with four response options each: not at all true, hardly true, moderately true, and exactly true, summed for a total score ranging from 10 to 40 ), as well as six locally-developed questions regarding the learning environment and perceptions of the peer assessment (see Figure 1 for a process flow chart).

Peer assessment comments were thematically coded by two researchers using constant comparative analysis. ${ }^{8}$ The average number of words students wrote in response to each of the three questions about their peers was calculated. An analysis using $\mathrm{G} *$ Power confirmed that the sample size $(\mathrm{N}=71)$ would be adequately sensitive to effects of Cohen's $d=0.5$, with 0.95 power ( $a=.05$, two-tailed). ${ }^{9}$ We performed paired-sample $t$ tests in IBM SPSS, Version 27, to determine whether there were differences between the pre- and post-peer assessment surveys. The SUNY Upstate Institutional Review Board deemed the study exempt.

\section{Results}

Students wrote an average of 19.52 words per peer when asked to describe their peer's strengths; 12.82 when asked to describe weaknesses; and 13.42 when asked about areas for improvement (Table 1). The most common strengths and recommendations for growth both related to participation. Participation style and frequency were cited as strengths in $85.2 \%$ of comments, while learner-specific versions of "participate more" (linked to a compliment or a specific statement about the student) were cited in $29.8 \%$ of the recommendations for "reaching the next level of performance." Table 1 includes comment themes, frequencies, and examples.

Of the 168 students who completed peer assessments, 71 (42.2\%) completed both pre- and postsurveys (Table 2). The preassessment mean on the Generalized Self-Efficacy Scale was 32.07 (SD 4.03) with a median of 33 (IQR 30-35); the postmean was 33.00 (SD 4.15) with a median of 33 (IQR 30-36). A paired-sample $t$ test indicated that the difference was significant $(P=.009)$, but the effect size, determined by Cohen's measure, was 
small $(d=0.32){ }^{4}$

Perceptions of the learning environment did not change after the peer assessments (Table 3), however there was a statistically significant decline in positive responses to the item, "I think that giving feedback to my peers will help me learn to give good feedback later on in my career" $(P=.041)$, though the effect size was small $(d=.22)$.

\section{Discussion}

While students did not find the experience of completing assessments of their peers optimally useful to their development as assessors, after reviewing the feedback given to them by peers, the overall self-efficacy of the cohort increased. Any increase in students' self-efficacy, especially after a small-scale intervention, suggests that the process may have benefits beyond the aim of enhancing performance.

We hypothesize that the process of assessing others was not fully useful because students did not receive feedback on the quality of their assessments. Course faculty only reviewed assessments to assure that students made a meaningful effort and demonstrated professionalism in their narrative comments. To date, most studies of peer assessment have not addressed how educators review peer assessment quality or remediate students who do not provide effective feedback ${ }^{10}$ and we recommend this for further study.

Although the study took place within a single course and institution and the effect sizes were small, these findings suggest a role for peer assessment, in spite of its previously-recognized limitations. This work has implications for the continued study of peer assessment in health professions education and lays the groundwork for larger-scale studies, comparing students across programs and institutions.

\section{Conclusion}

Peer assessment offers a potential strategy for enhancing student self-efficacy within the medical school environment that requires few resources to implement, relative to the potential benefits. Our findings support the need for further research with larger sample sizes, linked GSE and assessment results, multiple institutions, and students at other stages of training; for work utilizing measures of constructs beyond generalized selfefficacy and more sensitive measures of the learning environment; and for qualitative studies to better understand how students integrate peer feedback into their developing professional identities.

\section{Tables and Figures}


Figure 1: Project Process Flow Chart

[First 2 months of academic year]
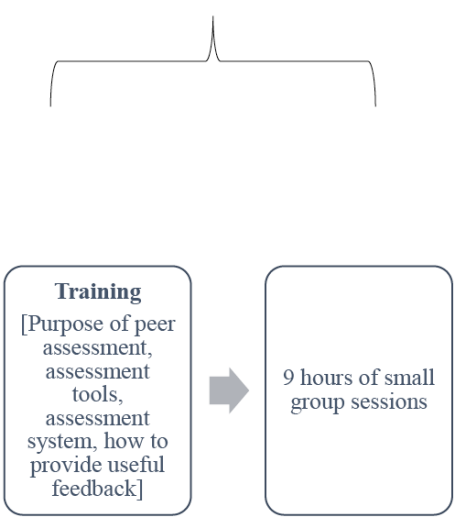

[3 week period in October/November]

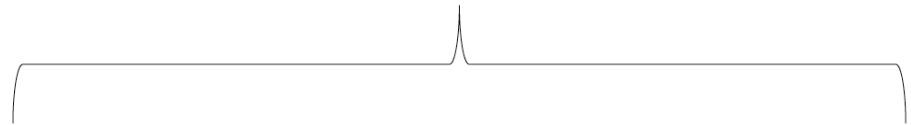

Post survey

[Generalized Self-

Efficacy; 6 locally developed

questions regarding the learning

[Generalized

-Efficacy; 6

locally

developed

questions
regarding the

regarding the

learning

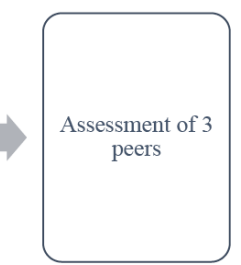

Read and reflect upon feedback from peers

collected in the

assessment process 
Table 1: Themes, Frequencies, and Sample Comments From Student Responses to Open-Ended Peer-Assessment Questions

Student Responses to, "What are the student's strengths?"

(500 Comments, Average Words/Peer=19.52, SD=3.4, Range: 6-81)

\begin{tabular}{|c|c|c|c|}
\hline Theme* & $\begin{array}{l}\text { \# of All } \\
\text { References }\end{array}$ & $\begin{array}{l}\% \text { of All } \\
\text { References }\end{array}$ & Sample Comments and Subthemes \\
\hline \multirow{2}{*}{ Participation } & \multirow{2}{*}{426} & \multirow[t]{2}{*}{$85.20 \%$} & $\begin{array}{l}\text { Reference to participation style } \mathbf{( 7 6 . 8 \% ) : ~ " [ F i r s t ~ n a m e ] ~ c o n s i s t e n t l y ~} \\
\text { participates in class. He asks questions to gain clarification and provides } \\
\text { information outside of his assigned question;" "Always has relevant } \\
\text { contributions to discussions which are fortified by personal experiences" }\end{array}$ \\
\hline & & & $\begin{array}{l}\text { Reference to participation frequency }(16.8 \%): \text { "...Always respectfully } \\
\text { contributes to conversation..." "consistently..." (see above) [emphasis } \\
\text { added] }\end{array}$ \\
\hline \multirow{2}{*}{$\begin{array}{l}\text { Preparation } \\
\text { (overall) }\end{array}$} & \multirow[b]{2}{*}{157} & \multirow[b]{2}{*}{$31.40 \%$} & $\begin{array}{l}\text { Prepared overall (31.4\%): "... clearly comes prepared..." "[First name] } \\
\text { always comes prepared and appears to have thought about the topic a } \\
\text { lot and considered different aspects of it." }\end{array}$ \\
\hline & & & $\begin{array}{l}\text { Prepared for preassigned questions (17\%): "...Answering assigned } \\
\text { questions thoroughly, plus being able to answer on-the-fly questions from } \\
\text { her research;" "The question that they are responsible for is answered } \\
\text { well." }\end{array}$ \\
\hline Respectful & 33 & $6.60 \%$ & "... is respectful of others talking." "...Respectfully joins discussion..." \\
\hline $\begin{array}{l}\text { Special point of } \\
\text { view (specific } \\
\text { training or } \\
\text { background) }\end{array}$ & 16 & $3.20 \%$ & $\begin{array}{l}\text { "She brings in personal stories (especially with the interpreter issue in the } \\
\text { office) with her own experiences which adds depth to the conversation." } \\
\text { "[First name] has a strong background in public health which helps him } \\
\text { understand the class concepts in a bigger picture." "...She contributed } \\
\text { to the conversation based on her own personal experience of being a } \\
\text { mom, and I felt like that helped the group get a different perspective..." } \\
\text { [emphasis added] }\end{array}$ \\
\hline \multicolumn{4}{|c|}{$\begin{array}{l}\text { Student Responses to, "What are the student's weaknesses?" } \\
\text { (500 Comments, Average Words/Peer=12.82, SD=12.4, Range: 1-73) }\end{array}$} \\
\hline Theme & $\begin{array}{l}\text { \# of } \\
\text { References }\end{array}$ & $\begin{array}{l}\% \text { of All } \\
\text { References }\end{array}$ & Sample Comments \\
\hline $\begin{array}{l}\text { Not fully } \\
\text { considerate of } \\
\text { other students }\end{array}$ & 43 & $8.60 \%$ & $\begin{array}{l}\text { "He participates a lot which is great but he may want to give some } \\
\text { others a chance to participate;" "Addresses instructors more often than } \\
\text { other students at times" }\end{array}$ \\
\hline $\begin{array}{l}\text { Direct reference } \\
\text { to assessment } \\
\text { criteria }\end{array}$ & 32 & $6.40 \%$ & $\begin{array}{l}\text { "Needs to draw more on knowledge from other sources such as prior } \\
\text { sessions and other courses;" "He can answer "what' questions easily and } \\
\text { should start working on being able to answer "why' questions involving } \\
\text { ethical principles." }\end{array}$ \\
\hline
\end{tabular}

(continued on next page) 
Table 1: Continued

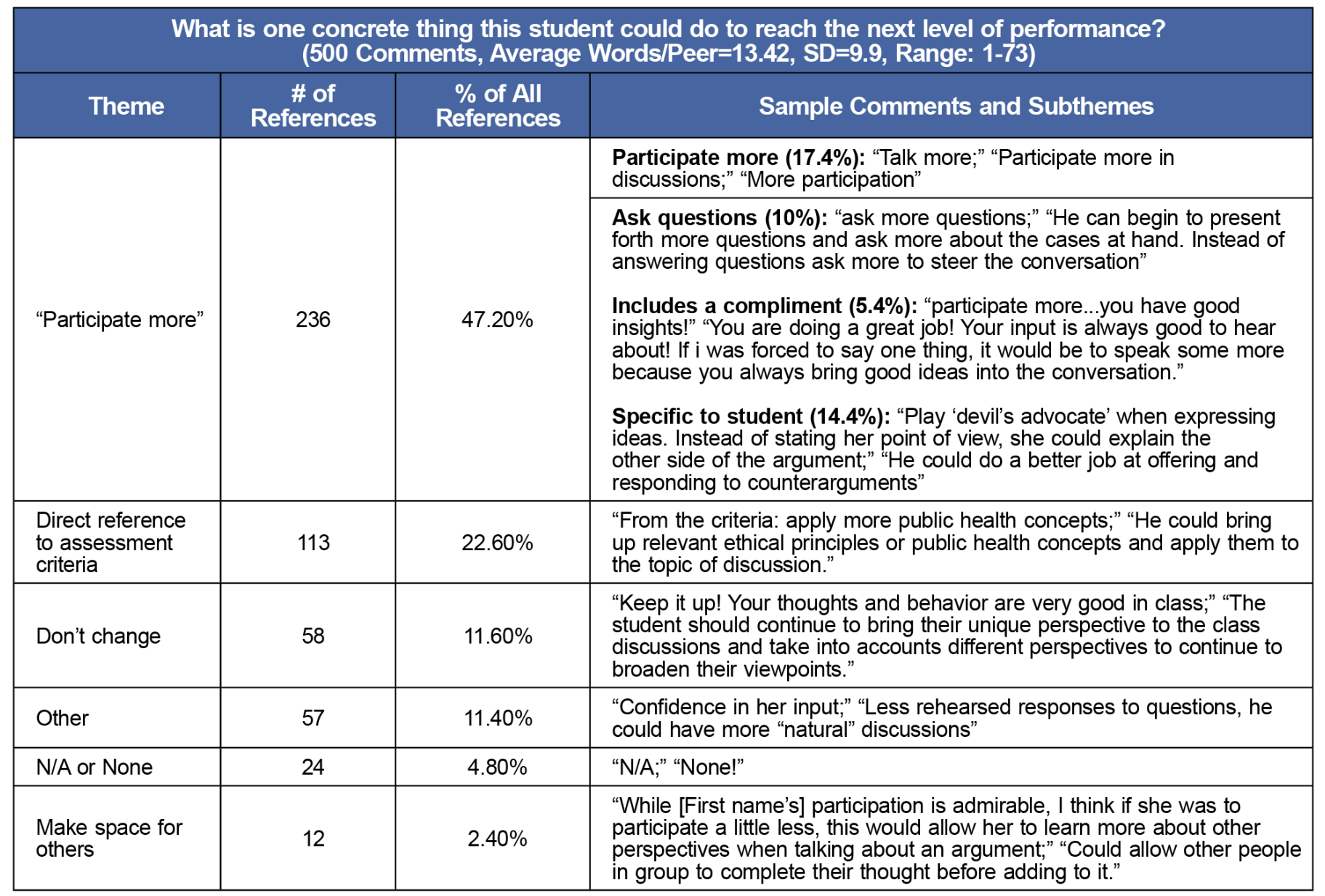

*In some cases, one student's comments reflected multiple themes so the sum of the percent column is $>100 \%$. 
Table 2: Results and Paired $\boldsymbol{t}$ Test Comparisons for Generalized Self-efficacy Items and Scale $(\mathbf{n}=71)$

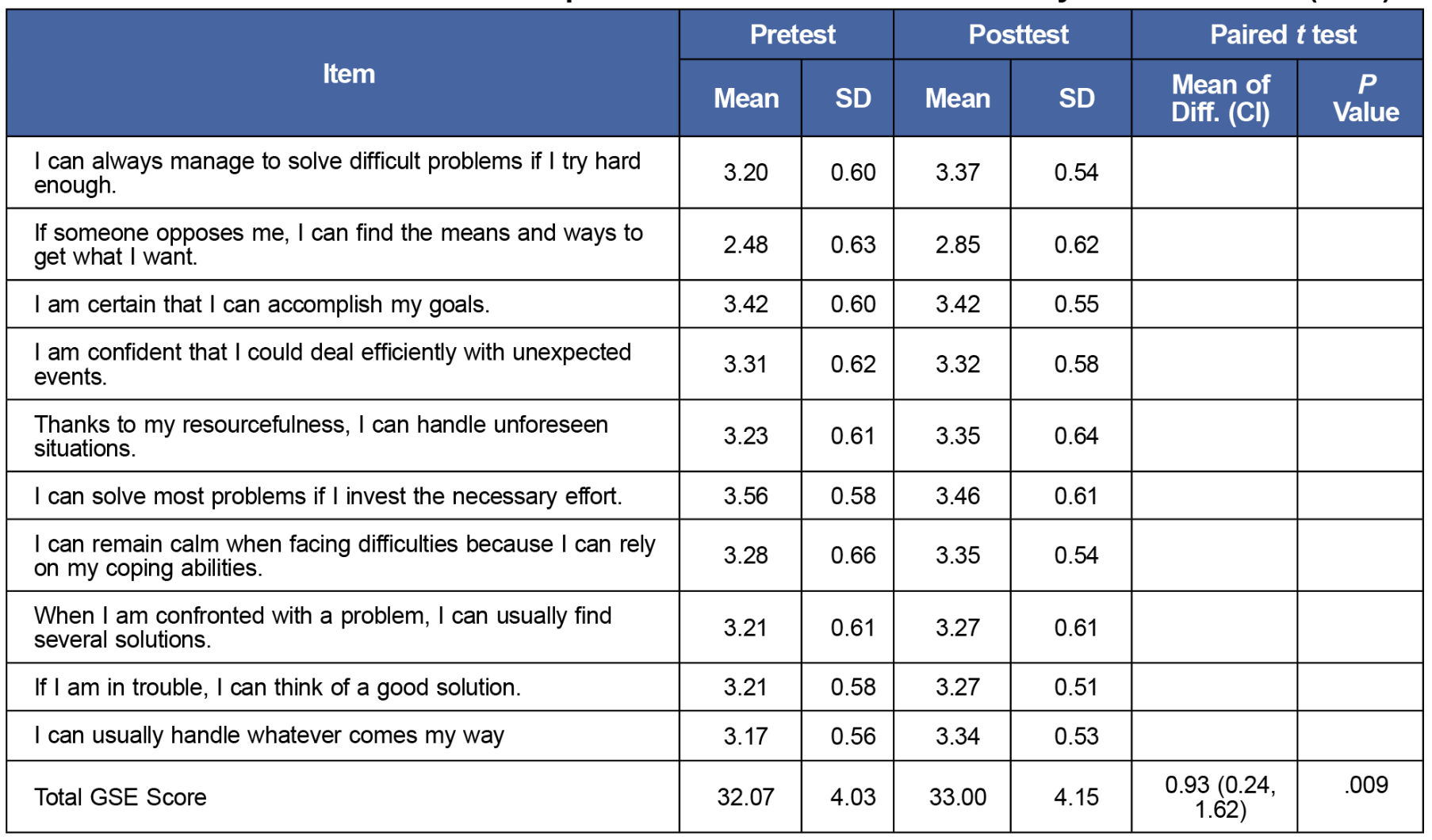

Abbreviation: GSE, Generalized Self-efficacy Scale

Table 3: Results and Paired $t$ Test Comparisons for Learning Environment and Assignment Feedback Items

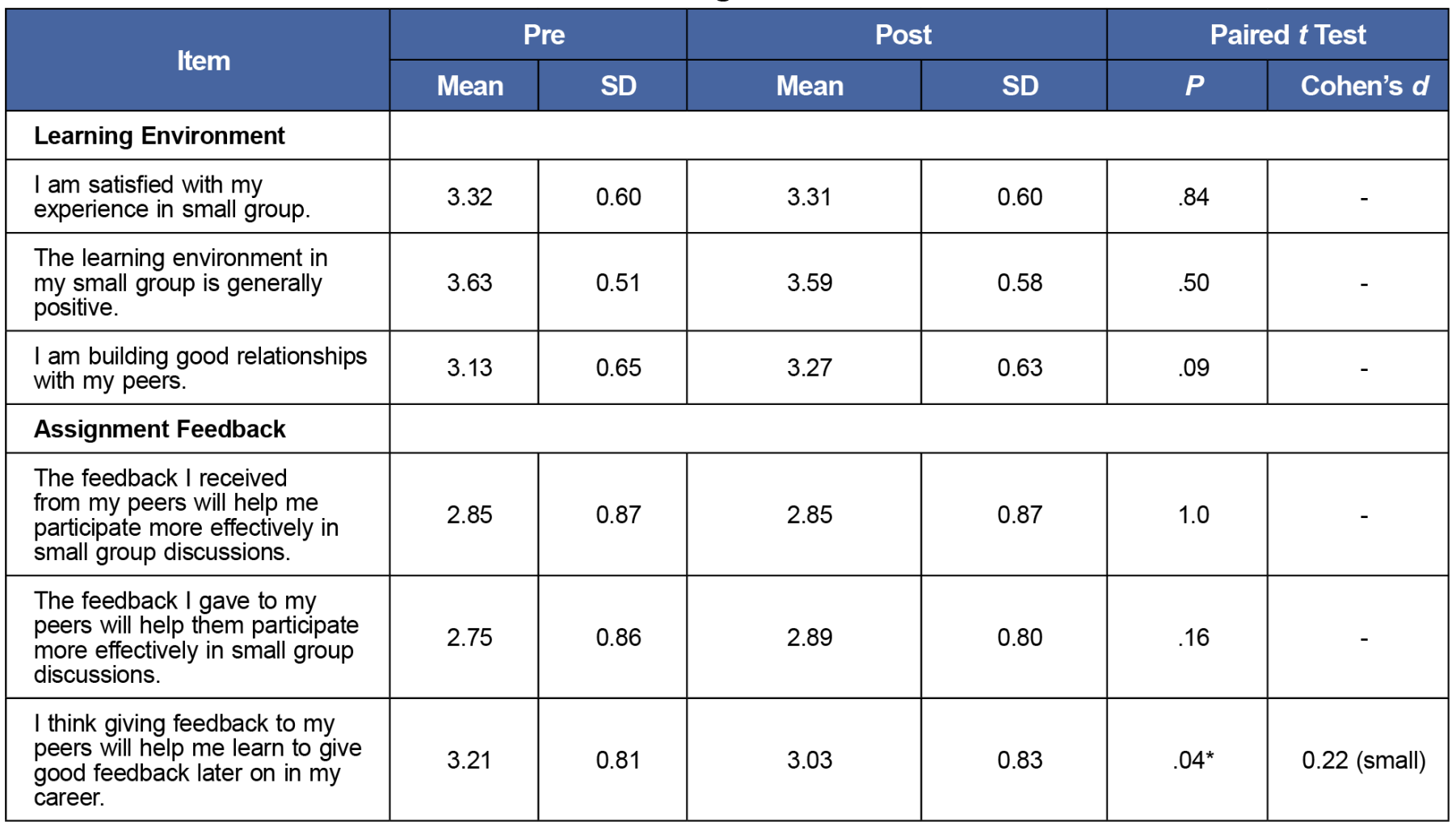

${ }^{*}$ Correlation is significant at the .05 level (2-tailed). 


\section{Acknowledgments}

The authors thank the students and faculty in the Patients to Populations course as well as the peer reviewers and editorial team at PRIMER.

\section{Corresponding Author}

Amy E. Caruso Brown, MD, MSc, MSCS

\section{Author Affiliations}

Lauren J. Germain, PhD, MEd - Office of Evaluation, Assessment and Research, SUNY Upstate Medical University, Syracuse, NY I Department of Public Health and Preventive Medicine, SUNY Upstate Medical University, Syracuse, NY

Hsin H. Li, DO, MPH - Garnet Health Medical Center, Middletown, NY

Amen Wiqas, BA - SUNY Upstate Medical University, Syracuse, NY

Lauren Zahn, MA - Center for Bioethics and Humanities, SUNY Upstate Medical University, Syracuse, NY

Telisa M. Stewart, DrPH - Department of Public Health \& Preventive Medicine, Department of Urology, and Department of Geriatrics, State University of New York Upstate Medical University, Syracuse, NY

Travis R. Hobart, MD, MPH - Department of Public Health and Preventive Medicine, SUNY Upstate Medical University, Syracuse, NY I Department of Pediatrics, SUNY Upstate Medical University, Syracuse, NY

Amy E. Caruso Brown, MD, MSc, MSCS - Center for Bioethics and Humanities, SUNY Upstate Medical University, Syracuse, NY I Department of Pediatrics, SUNY Upstate Medical University, Syracuse, NY

\section{References}

1. Adachi C, Tai JH, Dawson P. Academics' perceptions of the benefits and challenges of self and peer assessment in higher education. Assess Eval High Educ. 2018;43(2):294-306. doi:10.1080/02602938.2017.1339775

2. Speyer R, Pilz W, Van Der Kruis J, Brunings JW. Reliability and validity of student peer assessment in medical education: a systematic review. Med Teach. 2011;33(11):e572-e585. doi:10.3109/0142159X.2011.610835

3. AAMC. Use of assessment methods by US and Canadian Medical schools. In: AAMC Curriculum Inventory, 2012-2016. 2018. Association of American Medical Colleges. Accessed January 5, 2022. https://www.aamc.org/data-reports/curriculum-reports/report/curriculum-reports

4. Biesma R, Kennedy MC, Pawlikowska T, Brugha R, Conroy R, Doyle F. Peer assessment to improve medical student's contributions to team-based projects: randomised controlled trial and qualitative follow-up. BMC Med Educ. 2019;19(1):371. doi:10.1186/s12909-019-1783-8

5. Artino AR Jr, Dong T, DeZee KJ, et al. Development and initial validation of a survey to assess students' self-efficacy in medical school. Mil Med. 2012;177(9)(suppl):31-37. doi:10.7205/MILMED-D-12-00240

6. Klassen RM, Klassen JRL. Self-efficacy beliefs of medical students: a critical review. Perspect Med Educ. 2018;7(2):76-82. doi:10.1007/s40037-018-0411-3

7. Schwarzer R, Jerusalem M. Generalized Self-Efficacy scale. In: Weinman J, Wright S, Johnston M, eds. Measures in health psychology: A user's portfolio. Causal and control beliefs. Windsor, UK: NFERNELSON; 1995:35-37.

8. Glaser BG, Strauss AL. The Discovery of Grounded Theory: Strategies for Qualitative Research. New York: Aldine De Gruyter; 1967.

9. Faul F, Erdfelder E, Buchner A, Lang AG. Statistical power analyses using G*Power 3.1: tests for correlation and regression analyses. Behav Res Methods. 2009;41(4):1149-1160. 
doi:10.3758/BRM.41.4.1149

10. Lerchenfeldt S, Mi M, Eng M. The utilization of peer feedback during collaborative learning in undergraduate medical education: a systematic review. BMC Med Educ. 2019;19(1):321. doi:10.1186/s12909-019-1755-z

Copyright $@ 2022$ by the Society of Teachers of Family Medicine 